\title{
Polymorphisms in Heat Shock Proteins A1B and A1L (HOM) as Risk Factors for Oesophageal Carcinoma in Northeast India
}

\author{
Snigdha Saikia ${ }^{1,2}$, Prajjalendra Barooah ${ }^{1,2}$, Mallika Bhattacharyya ${ }^{2}$, Manab \\ Deka $^{1}$, Bhabadev Goswami², Manash P Sarma ${ }^{3}$, Subhash Medhi ${ }^{1 *}$
}

\begin{abstract}
Background: To investigate polymorphisms in heat shock proteins A1B and A1L (HOM) and associated risk of oesophageal carcinoma in Northeast India. Materials and Methods: The study includes oesophageal cancer (ECA) patients attending general outpatient department (OPD) and endoscopic unit of Gauhati Medical College. Patients were diagnosed based on endoscopic and histopathological findings. Genomic DNA was typed for HSPA1B1267 and HSPA1L2437 SNPs using the polymerase chain reaction with restriction fragment length polymorphisms. Results: A total of 78 cases and 100 age-sex matched healthy controls were included in the study with a male: female ratio of 5:3 and a mean age of $61.4 \pm 8.5$ years. Clinico-pathological evaluation showed $84 \%$ had squamous cell carcinoma and 16\% were adenocarcinoma. Dysphagia grades 4 (43.5\%) and $5(37.1 \%)$ were observed by endoscopic and hispathological evaluation. The frequency of genomic variation of A1B from wild type $A / A$ to heterozygous $A / G$ and mutant $G / G$ showed a positive association [chi $s q=19.9, p=<0.05]$ and the allelic frequency also showed a significant correlation [chi sq=10.3, with cases vs. controls, $O R=0.32, p \leq 0.05]$. The genomic variation of $A 1 \mathrm{~L}$ from wild $\mathrm{T} / \mathrm{T}$ to heterozygous $\mathrm{T} / \mathrm{C}$ and mutant $\mathrm{C} / \mathrm{C}$ were found positively associated [chi sq=7.02, p<0.05] with development of ECA. While analyzing the allelic frequency, there was no significant association [chi $\mathrm{sq}=3.19, \mathrm{OR}=0.49, \mathrm{p}=0.07]$. Among all the risk factors, betel quid $[\mathrm{OR}=9.79, \mathrm{Chi}$ square $=35.0$, $\mathrm{p}<\mathbf{0 . 0 5}]$, tobacco $[\mathrm{OR}=\mathbf{2 . 9 5}$, chi square $=10.6, \mathrm{p}<0.05]$, smoking $[\mathrm{OR}=3.23$, chi square $=10.1, \mathrm{p}<0.05]$ demonstrated significant differences between consumers vs. non consumers regarding EC development. Alcohol did not show any significant association $[O R=1.34$, chi square $=0.69, p=0.4]$ independently. Conclusions: It can be concluded that the present study provides marked evidence that polymorphisms of HSP70 A1B and HSP70 A1L genes are associated with the development of ECA in a population in Northeast India, A1B having a stronger influence. Betel quid consumption was found to be a highly significant risk factor, followed by smoking and tobacco chewing. Although alcohol was not a potent risk factor independently, alcohol consumption along with tobacco, smoking and betel nut was found to contribute to development of ECA.
\end{abstract}

Keywords: Oesophageal cancer - heat shock proteins - HSPA1B1267 and HSPA1L2437 - risk factors

Asian Pac J Cancer Prev, 16 (18), 8227-8233

\section{Introduction}

Oesophageal cancer (ECA) is the eighth most common type of cancer worldwide (Zhang et al., 2009). Squamous cell carcinoma of the oesophagus is the third leading cancer in men and fourth leading cancer in women in India. In India the highest incidence of ECA patients are recorded in Assam and rest of the North eastern region of India (Chitra et al., 2004).

Only about $10 \%$ of the ECA patients show a 5-year survival rate, this is mainly due to the symptomless progression in the early stages of cancer and poor prognosis (Yang et al., 2010). Oesophageal cancer occurs in two main histopathological types; squamous cell carcinoma (SCC) and adenocarcinoma (ADC). Squamous cell carcinoma, in most cases; occur in the middle or upper one third of the oesophagus and adenocarcinoma in the lower one third or Gastro-Oesophageal Junction (Ke et al., 2002). Both external and internal factors contribute to the pathogenesis of ECA. The external factors are mainly related to different life style factors and habits and internal factors are the genetic variations. Epidemiological studies indicate that betel nut, alcohol and tobacco consumption along with smoking are major risk factors for ECA (Chen et al., 2011).

HLA polymorphism is implicated in conferring genetic

${ }^{I}$ Department of Bioengineering and Technology, Laboratory of Molecular Virology and Oncology, Gauhati University Institute of Science and Technology, Gauhati University, ${ }^{2}$ Department of Gastroenterology, Gauhati Medical College Hospital, ${ }^{3}$ Department of Biotechnology, Assam Down Town University, Guwahati, India*For correspondence: medhi_79@yahoo.co.uk 
susceptibility to a large number of immune-mediated diseases, including some cancers in several populations including Asian and African populations (Kummee et al., 2007). HLA-linked, heat shock protein 70 (HSP70) genes are of particular interest because their involvement in tumor immunity and cancer pathogenesis makes them cancer susceptibility candidate genes (Rohde et al., 2005).

Heat shock proteins are highly conserved proteins expressed in normal physiological condition at low levels but their expression increase in response to a variety of stress stimuli, including free radical, toxic metal ion exposure etc. Moreover, pathological stimuli such as hormonal overstimulation or viral/bacterial infection can induce a substantial increase of intracellular synthesis and secretion of Hsp proteins. Hsp proteins are divided in to six families based on their molecular weight. Hsp70 is encoded by a single exon of 1926 bp and its protein includes 641 amino acids (Meimaridou et al., 2009). Hsp70 protein is expressed across mammalian species both constitutively and in response to cellular stress or injury (Boiocchi et al., 2014). The functions of Hsp70 within the cell are primarily homeostatic in nature and include assistance with protein folding and prevention of protein aggregation and as inductors of anti apoptotic mechanisms (Lovett et al., 2014). But when released to extracellular space, Hsp70 acts as a potent damageassociated molecular pattern (DAMP) to stimulate the innate and adaptive immune response via interactions with Toll like receptor (TLR) 2 and TLR4, resulting in the release of proinflammatory cytokines such as IL1 beta, TNF-alpha, and IFN-beta (Vabulas et al., 2002). In addition Hsp70 promotes ubiquitination and degradation of misfolded proteins (Asea et al., 2000).

Some of the genes encoding the Hsp proteins which have been well studied and characterized are Hsp701, Hsp70-2 (HspA1B) and Hsp70-Hom (A1L). These genes are located in class III region of the human Major Histocompatibility Complex (MHC) on chromosome 6 (Daugaard et al., 2007). HspA1A and HspA1B genes encode an identical protein, the Hsp70 protein, whereas the HspA1L gene encodes a non heat inducible protein that shares $90 \%$ sequence identity with Hsp70 protein (Milner et al., 1992). It has been proposed that the Hsp70 plays an important role in tumor development, treatment, and prognosis and has distinct immunologic mechanisms affecting tumor cells and promoting cell growth (Wang et al., 2005). In cancer cells, the expression of Hsp70 is abnormally high and the protein may participate in oncogenesis and in resistance to chemotherapy. Several single nucleotide polymorphisms (SNPs) have been described in these genes which are still under intense scrutiny for possible association as risk factors to different cancers (Favatier et al., 1997). Predisposition to cancer may be conferred by genetic polymorphisms that arise from SNPs in certain pertinent genes (Hanahan et al., 2011). These genetic polymorphisms might partly explain the individual differences in susceptibility towards ECA. Since the population in the North eastern states of India is ethically distinct, the genetic makeup may render this population to be more susceptible towards development of ECA in association with certain high risk habits.

\section{Materials and Methods}

\section{Patient population}

The study includes 78 cases and 100 age and sex matched healthy controls attending the outdoor and endoscopic unit at Department of Gastroenterology, Gauhati Medical College Hospital, Guwahati, for the period of April 2012 to April 2014 with prior consent. Patients observed to have abnormal ulceroproliferative growth in any part of the oesophagus were selected. Endoscopic biopsy samples were taken and histopathological evaluation was performed to confirm diagnosis of cancer. Disease history was recorded for all subjects, along with life style factors and habits like history of alcohol consumption, betel nut chewing, tobacco chewing, smoked food and smoking. Patients were categorized on the basis of histopathological report or dysphagia grade based on modified O'Rourke dysphagia grading system (Waters et al., 2002).

\section{Sample preparation}

$4 \mathrm{ml}$ of whole blood was collected in EDTA vials by simple venipuncture method from ECA patients and stored at $4^{\circ} \mathrm{C}$. Genomic DNA was isolated from whole blood using standard technique (Sambrook et al., 1990).

\section{PCR and RFLP analysis for AIB and AlL(HOM) genes}

A1B:DNA samples were amplified with product size $1117 \mathrm{bp}$ for $\mathrm{A} 1 \mathrm{~B}$ using primers 5'-CATCGACTTC TACACGTCCA-3' (forward) and 5'-CAAAGTCCTTGAGTCCCAAC-3' (reverse) and subjected to restriction digestion with PstI (Thermo scientific) as previously described (Chouchane et al., 1997) The DNA-lacking polymorphic PstI site 1267 (rs1061581) within the HSPA1B gene generates a product of $1117 \mathrm{bp}$ after restriction in case of the A allele, whereas the PstI site produced two fragments of 936 and $181 \mathrm{bp}$ for the $G$ allele.

A1L: PCR amplification for A1L was done using primers 5'-GGACAAGTCTGAGAAGGTAC AG-3' (forward) and 5'-GTAACTTAGATTCAGGTCTGG-3' (reverse) with product size of $878 \mathrm{bp}$ and subjected to restriction digestion with NcoI (Thermo Scientific) as previously described (Chouchane et al., 1997). At allele position $2437 \mathrm{~T} / \mathrm{C}$ (rs2227956) the presence of two fragments of $551 \mathrm{bp}$ and $327 \mathrm{bp}$ represents the $\mathrm{T}$ allele whereas the undigested $878 \mathrm{bp}$ product represents the $\mathrm{C}$ allele.

\section{Statistical analysis}

Genotypic and allelic frequencies were compared by using the Mantel-Haenzel, chi-square test or the Fisher's exact test. Statistical significance was defined as $\mathrm{p}<0.05$. Strength of association rate was assessed by odds ratio (OR) statistics. The statistical tool EPIINFO (version 7; July 2014) was used.

\section{Results}

\section{Demographic features}

A total of 100 age and sex matched healthy controls 
Polymorphisms in Heat Shock Proteins A1B and A1L (HOM) as Risk Factors for Oesophageal Carcinoma in Northeast India

with no previous indication of malignancy along with 78 ECA cases were included in this study. Sex ratio was $5: 3$ (M:F), with mean age of $61.4 \pm 8.52$ years. The mean duration of dysphagia for patients was found to be $84 \pm 64$ days. The distribution of cases and controls are shown in Table:1. Highest number of cases were in the age group 65-74 years. Male-preponderance was observed. Majority of the cases were from rural area with higher illiteracy.

\section{Clinico-pathological evaluation}

Clinico-pathological evaluation showed $84 \%$ patients developed tumor at upper end of the oesophagus with pathologically distinguished squamous cell carcinoma and $16 \%$ were evaluated as adenocarcinoma with tumor growth at lower end of the oesophagus or GE junction. Endoscopic evaluation showed majority of the patients with dysphagia grade 4 (43.5\%) and 5 (37.1\%) (Table 2).

Table 1. Demographic Characteristics of Oesophageal Cancer and Healthy Controls Included in the Study

\begin{tabular}{ccc}
\hline Characterisics & $\begin{array}{c}\text { Cases } \\
\mathrm{N}=78(\%)\end{array}$ & $\begin{array}{c}\text { Controls } \\
\mathrm{N}=100(\%)\end{array}$ \\
\hline Age $(\mathrm{yrs})$ & & \\
$<25$ & $1(1.3)$ & $6(6.0)$ \\
$25-34$ & $1(1.3)$ & $4(4.0)$ \\
$35-44$ & $7(8.9)$ & $8(8.0)$ \\
$45-54$ & $16(20.5)$ & $20(20.0)$ \\
$55-64$ & $23(29.4)$ & $30(30.0)$ \\
$65-74$ & $26(33.3)$ & $28(28.0)$ \\
$75+$ & $4(5.1)$ & $4(4.0)$ \\
Sex & & \\
Male & $46(58.9)$ & $70(70.0)$ \\
Female & $32(41.0)$ & $30(30.0)$ \\
Residence & & \\
Urban & $26(33.3)$ & $58(58.0)$ \\
Rural & $52(66.6)$ & $42(42.0)$ \\
Education & & \\
Literate & $32(41.1)$ & $84(84.0)$ \\
Illiterate & $46(58.9)$ & $16(16.0)$ \\
\hline
\end{tabular}

Table 2. The modified O'Rourke dysphagia staging system (Stages of Swallowing status)

\begin{tabular}{llc}
\hline Stage & \multicolumn{1}{c}{$\begin{array}{c}\text { Magnitude } \\
\text { of Symptoms }\end{array}$} & $\begin{array}{c}\text { PercentageN=78 (\%) } \\
\text { of Patients }\end{array}$ \\
\hline 1 & Asymptomatic & $4(5.12)$ \\
2 & Solids with some dysphagia & $5(6.41)$ \\
3 & Soft or pureed food only & $6(7.6)$ \\
4 & Liquids only & $34(43.5)$. \\
5 & No swallowing at all & $29(37.1)$ \\
\hline
\end{tabular}

Correlation between different life style factors and habits in cases and controls

Among all the life style factors and habits, betel quid $[\mathrm{OR}=9.79$, chi square $=35.0, \mathrm{p}<0.05]$, tobacco $[\mathrm{OR}=2.95$, chi square $=10.6, p<0.05]$, smoking $[O R=3.23$, Chi square $=10.1, \mathrm{p}<0.05]$ has significant correlation when compared with healthy controls between consumers and nonconsumers. (Table:4)

Association of Hsp A1B gene and oesophageal cancer

While analyzing the frequency of genomic variation of A1B from wild type A/A to heterozygous $A / G$ and mutant $\mathrm{G} / \mathrm{G}$ with cases vs. controls, a positive association was found [chi sq=19.9, p<0.05] and the allelic frequency also showed a significant correlation [chi $\mathrm{sq}=10.3, \mathrm{OR}=0.32$; $\mathrm{p}<0.05]$. These results may indicate that the variation in A1B genotype can be relative risk to develop ECA [Table 3]

While taking the history of patient regarding their food habits and life style we observed the combined consumption of different food habits of smoking, tobacco, alcohol, betel nut. This combination has been shown in Table5. Statistical analysis showed that different combination of these food habits gives a significant association to develop the genetic variation in A1B gene in ECA. Significant association was seen in case of combination of

smoking \& alcohol [chi sq=51.8, OR=10.5, p<0.05]; smoking \& betel nut [chi sq=29.7, $\mathrm{OR}=0.19, \mathrm{p}<0.05]$; smoking \& tobacco [chi sq $=8.05, \mathrm{OR}=0.15, \mathrm{p}<0.05]$; alcohol \& betel nut [chi sq=5.91, OR=4.05, $<<0.05$ ]; betel nut $\&$ tobacco [chi sq=20.5, OR=0.26, p<0.05]; smoking ,

Table 4. Correlation between Different Life Style Factors and Habits in Patients with Oesophageal Cancer Cases and Healthy Controls

\begin{tabular}{lccccc}
\hline Factors & $\begin{array}{c}\text { Case } \\
\mathrm{N}=78(\%)\end{array}$ & $\begin{array}{c}\text { Control } \\
\mathrm{N}=100(\%)\end{array}$ & $\begin{array}{c}\text { OR } \\
\text { square }\end{array}$ & $\begin{array}{c}\text { Chi- } \\
\text { squer }\end{array}$ \\
\hline Betel Quid & & & & & \\
$\quad$ Chewers & $70(89.7)$ & $24(30.7)$ & 9.79 & 35 & $<0.05$ \\
$\quad$ Non chewers & $8(10.2)$ & $26(33.3)$ & & & \\
Tobacco & & & & & \\
$\quad$ Chewers & $46(58.9)$ & $16(20.5)$ & 2.95 & 10.6 & $<0.05$ \\
$\quad$ Non chewers & $32(41)$ & $34(43.5)$ & & & \\
$\begin{array}{l}\text { Smoking } \\
\quad \text { Smokers }\end{array}$ & $37(47.4)$ & $11(14.1)$ & 3.23 & 10.8 & $<0.05$ \\
$\quad$ Non Smokers & $41(52.5)$ & $39(50)$ & & & \\
Alcohol & & & & & \\
$\quad \begin{array}{l}\text { Drinker } \\
\quad 26(33.3)\end{array}$ & $18(23)$ & 1.34 & 0.69 & 0.4 \\
$\quad$ Non drinker & $52(44.4)$ & $32(41)$ & & & \\
\hline
\end{tabular}

Table 3. Genomic and Allelic Frequency of A1B gene in Esophageal Cancer Patients with Respect to Control Sample

\begin{tabular}{lcccccccccc}
\hline & \multicolumn{3}{c}{ Genomic Frequency } & & & & \multicolumn{3}{c}{ Allelic Frequency } \\
A1B & $\mathrm{A} / \mathrm{An}(\%)$ & $\mathrm{A} / \mathrm{G} \mathrm{n}(\%)$ & $\mathrm{G} / \mathrm{G} \mathrm{n}(\%)$ & Chi-square & P value & $\mathrm{An}(\%)$ & $\mathrm{G} \mathrm{n}(\%)$ & Chi-square & P value & OR \\
\hline Case $(\mathrm{n}=78)$ & $29(37.1)$ & $12(15.3)$ & $37(47.4)$ & 19.9 & $<0.05$ & $70(45)$ & $86(55)$ & 10.3 & $<0.05$ & 0.32 \\
Control $(\mathrm{n}=100)$ & $62(62)$ & $20(20)$ & $18(18)$ & & & $144(72)$ & $56(28)$ & & & \\
\hline A1L & $\mathrm{TT}(\%)$ & $\mathrm{TC}(\%)$ & $\mathrm{CC}(\%)$ & Chi-square & P value & $\mathrm{T}(\%)$ & $\mathrm{C}(\%)$ & Chi-square & P value & OR \\
\hline Case $(\mathrm{n}=78)$ & $48(61.5)$ & $28(35.8)$ & $2(2.5)$ & 7.02 & $<0.05$ & $124(79)$ & $32(20.5)$ & 3.19 & 0.07 & 0.49 \\
Control $(\mathrm{n}=100)$ & $78(78)$ & $22(22)$ & 0 & & & $178(89)$ & $44(11)$ & & & \\
\hline
\end{tabular}


Table 5. Genomic Distribution of A1B gene in Different Combinations of Life Style Factors and Habits in Cases and Control

\begin{tabular}{|c|c|c|c|c|c|}
\hline A1B & $\mathrm{A} / \mathrm{A} \mathrm{n}(\%)$ & $\mathrm{A} / \mathrm{G}+\mathrm{G} / \mathrm{G}$ n $(\%)$ & Chi square & OR & $P$ value \\
\hline \multicolumn{6}{|l|}{ Smoking \& Alcohol } \\
\hline Cases $(\mathrm{N}=17)$ & $11(64.7)$ & $7(35.3)$ & 51.8 & 10.5 & $<0.05$ \\
\hline Control (N=28) & $4(14.3)$ & $24(85.7)$ & & & \\
\hline \multicolumn{6}{|l|}{ Smoking \& Betel nut } \\
\hline Cases $(\mathrm{N}=33)$ & $13(39.4)$ & $20(60.6)$ & 29.7 & 0.19 & $<0.05$ \\
\hline Control $(\mathrm{N}=18)$ & $14(77.8)$ & $4(22.2)$ & & & \\
\hline \multicolumn{6}{|l|}{ Smoking \&Tobacco } \\
\hline Cases $(\mathrm{N}=18)$ & $8(44.5)$ & $10(55.5)$ & 8.05 & 0.15 & $<0.05$ \\
\hline Control $(\mathrm{N}=24)$ & $22(91.6)$ & $4(8.4)$ & & & \\
\hline \multicolumn{6}{|l|}{ Alcohol \& Betel nut } \\
\hline Cases $(\mathrm{N}=22)$ & $14(64)$ & $8(36)$ & 5.91 & 4.05 & $<0.05$ \\
\hline Control $(\mathrm{N}=26)$ & $8(31)$ & $18(69)$ & & & \\
\hline \multicolumn{6}{|l|}{ Alcohol\&Tobacco } \\
\hline Cases $(\mathrm{N}=18)$ & $11(61.1)$ & $7(38.9)$ & 1.4 & 0.7 & 0.23 \\
\hline Control $(\mathrm{N}=26)$ & $18(69.2)$ & $8(30.8)$ & & & \\
\hline \multicolumn{6}{|l|}{ Betelnut \&Tobacco } \\
\hline Cases $(\mathrm{N}=42)$ & $16(38)$ & $26(62)$ & 20.5 & 0.26 & $<0.05$ \\
\hline Control $(\mathrm{N}=20)$ & $14(70)$ & $6(30)$ & & & \\
\hline \multicolumn{6}{|c|}{ Smoking \&Alcohol\&Betel nut } \\
\hline Cases $(\mathrm{N}=15)$ & $9(60)$ & $6(40)$ & 1.05 & 0.74 & 0.76 \\
\hline Control $(\mathrm{N}=12)$ & $8(67)$ & $4(33)$ & & & \\
\hline \multicolumn{6}{|c|}{ Smoking \&Alcohol\&Tobacco } \\
\hline Cases $(\mathrm{N}=11)$ & $6(54.5)$ & $5(45.5)$ & 57.7 & 0 & $<0.05$ \\
\hline Control $(\mathrm{N}=4)$ & $4(100)$ & 0 & & & \\
\hline \multicolumn{6}{|c|}{ Smoking \&Alcohol\&Tobacco\&Betelnut } \\
\hline Cases $(\mathrm{N}=7)$ & $3(43)$ & $4(57)$ & 7.18 & 2.26 & $<0.05$ \\
\hline Control $(\mathrm{N}=8)$ & $2(25)$ & $6(75)$ & & & \\
\hline
\end{tabular}

Table 6. Genomic Distribution of A1L gene in Different Combinations of Life Style Factors and Habits in Cases and Control

\begin{tabular}{|c|c|c|c|c|c|}
\hline A1L & $\mathrm{T} / \mathrm{T} \mathrm{n}(\%)$ & $\mathrm{T} / \mathrm{C}+\mathrm{C} / \mathrm{C} \mathrm{n}(\%)$ & Chi square & OR & $\mathrm{P}$ value \\
\hline \multicolumn{6}{|l|}{ Smoking \& Alcohol } \\
\hline Cases $(\mathrm{N}=18)$ & $13(72.2)$ & $5(27.8)$ & 9.16 & 0.32 & $>0.05$ \\
\hline Control $(\mathrm{N}=18)$ & $16(89)$ & $2(11)$ & & & \\
\hline \multicolumn{6}{|l|}{ Smoking \& Betel nut } \\
\hline Cases $(\mathrm{N}=33)$ & $25(76)$ & $8(24)$ & 5.82 & 0.39 & $>0.05$ \\
\hline Control $(\mathrm{N}=12)$ & $10(83.3)$ & $2(16.7)$ & & & \\
\hline \multicolumn{6}{|l|}{ Smoking \&Tobacco } \\
\hline Cases $(\mathrm{N}=17)$ & $13(76.4)$ & $4(23.6)$ & 9.71 & 2.67 & $<0.05$ \\
\hline Control $(\mathrm{N}=22)$ & $12(54.5)$ & $10(45.5)$ & & & \\
\hline \multicolumn{6}{|l|}{ Alcohol \& Betel nut } \\
\hline Cases $(\mathrm{N}=22)$ & $15(68.1)$ & $7(31.9)$ & 1.38 & 1.42 & 0.23 \\
\hline Control $(\mathrm{N}=30)$ & $18(60)$ & $12(40)$ & & & \\
\hline \multicolumn{6}{|l|}{ Alcohol\&Tobacco } \\
\hline Cases $(\mathrm{N}=18)$ & $12(66.6)$ & $6(33.4)$ & 9.99 & 0.33 & $<0.05$ \\
\hline Control $(\mathrm{N}=14)$ & $12(85.7)$ & $2(14.3)$ & & & \\
\hline \multicolumn{6}{|l|}{ Betelnut \&Tobacco } \\
\hline Cases $(\mathrm{N}=41)$ & 27 (66) & $14(34)$ & 17.2 & 0.2 & $<0.05$ \\
\hline Control $(\mathrm{N}=22)$ & $20(91)$ & $2(9)$ & & & \\
\hline \multicolumn{6}{|c|}{ Smoking \&Alcohol\&Betel nut } \\
\hline Cases $(\mathrm{N}=15)$ & $11(73.3)$ & $4(26.7)$ & 31.9 & 5.49 & $<0.05$ \\
\hline Control $(\mathrm{N}=12)$ & $4(33.3)$ & $8(66.7)$ & & & \\
\hline \multicolumn{6}{|c|}{ Smoking \&Alcohol\&Tobacco } \\
\hline Cases $(\mathrm{N}=11)$ & $8(73)$ & $3(27)$ & 45.87 & 8.11 & $<0.05$ \\
\hline Control $(\mathrm{N}=8)$ & $2(25)$ & $6(75)$ & & & \\
\hline \multicolumn{6}{|c|}{ Smoking \&Alcohol\&Tobacco\&Betelnut } \\
\hline Cases $(\mathrm{N}=12)$ & $9(75)$ & $3(25)$ & 1.55 & 1.48 & 0.21 \\
\hline Control $(\mathrm{N}=6)$ & $4(67)$ & $2(33)$ & & & \\
\hline
\end{tabular}


Polymorphisms in Heat Shock Proteins A1B and AlL (HOM) as Risk Factors for Oesophageal Carcinoma in Northeast India

alcohol \& tobacco [chi sq=57.7, OR=0; $<<0.05]$; smoking , alcohol, tobacco \& betel nut [chi $\mathrm{sq}=7.18, \mathrm{OR}=2.26$, $\mathrm{p}<0.05]$.

Association of Hsp AlL gene and oesophageal cancer

The genomic variation of $\mathrm{A} 1 \mathrm{~L}$ from wild $\mathrm{T} / \mathrm{T}$ to heterozygous $\mathrm{T} / \mathrm{C}$ and mutant $\mathrm{C} / \mathrm{C}$ were found positively associated [chi $\mathrm{sq}=7.02 ; \mathrm{p}=<0.05$ ] to develop ECA when analyzed in cases vs. control. While analyzing the allelic frequency there was not any significant association [chi $\mathrm{sq}=3.19, \mathrm{OR}=0.49, \mathrm{p}=0.07]$. [Table 3]

The patient history of their food habits and life style were analyzed in different combination. The statistical analysis of combined consumption of different food habits of smoking, tobacco, alcohol, betel nut was done. This combination has been shown in Table 6 . Significant correlation was found in genomic distribution of A1L, between cases and controls in combined consumption of smoking \& alcohol [chi sq=9.16, OR=0.32; $<<0.05$ ]; smoking \& betel nut [chi sq=5.82, OR=0.39; $\mathrm{p}<0.05]$; smoking \& tobacco [chi sq=9.71, OR=2.67, $\mathrm{p}<0.05$ ]; alcohol \& tobacco [chi sq=9.99, OR=0.33, p<0.05]; betel nut $\&$ tobacco [chi sq=17.2, OR=0.2, p<0.05]; smoking , alcohol \& betel nut [chi sq=31.9, OR=5.49, p<0.05]; smoking, alcohol \& tobacco [chi sq $=45.87$, OR=8.81, $\mathrm{p}<0.05$ ]. [Table 6]

\section{Discussion}

Oesophageal cancer is a common and polygenic malignant cancer caused by complex interactions between genetic and environmental factors. The demographic distribution showed male predominance in these patients in the age group of 65-74years. Majority of the cases were from rural having poor literacy rate. Ganesh et al., 2009 also reported the male predominance in another population with higher age group in Mumbai, Western India. This study reveals high incidence of ECA in males with higher consumption of betel quid, tobacco, alcohol and smoking habits. In a trend similar to previously reported studies in South Indian population (Chitra et al., 2004) Squamous cell carcinoma was found to be the more dominant over adenocarcinoma in Northeast Indian population.

Among studied risk factors betel quid, tobacco, smoking and alcohol, we found betel quid to be strongly associated and potent risk factor in development of ECA in comparison with controls from Northeast India. Similar association has also been reported for betel quid in Indian population as a whole (Akhtar et al., 2012) and from North east India (Kurkalang et al., 2014) previously. Smoking and ECA have been associated by other studies from different regions of the world (Dar et al., 2012; Wang et al., 2015). Our study also corroborates these findings. Tobacco consumption has been consistently reported to be a high risk factor for ECA in various studies (Yang et al., 2005; Ganesh et al., 2009). In a previous study in the same population, the risk associated with chewing of betel nut was found to be higher than those for tobacco, smoking and alcohol consumption at all levels of consumption (Phukan et al., 2001).

Alcohol consumption was found to be a non significant risk factor for oesophageal carcinoma in our study.
Prabhu et al., 2013 reported that there was no role of alcohol in development of ECA in Asian population. In another study conducted in Western Maharashtra, alcohol consumption percentage was the least among other risk factors such as tobacco chewing and smoking (Giri et al., 2014) among ECA patients. Alcohol had very little effect on development of ECA whereas smoking was found to be a fivefold more potent risk factor (Holmes et al., 2007). Contrasting data have also been reported where positive correlation of alcohol on ECA was shown (Pandeya et al., 2009). In some of the earliest studies in the Indian population alcohol drinking was shown to be a significant risk factor (Gopala et al., 2013). Combined effect of Alcohol and tobacco or betel quid consumption in the development of ECA has been previously documented (Lee et al., 2005). Our study has also revealed similar scenario of synergistic effect of alcohol consumption along with smoking, betel quid and tobacco.

Genetic variants of HSP70 (A1B1267 and A1L2437) was evaluated previously as a risk to develop chronic hepatitis and hepatocellular carcinoma in Indian population where A1B1267 was more significant to develop the disease than A1L2437 (Medhi et al., 2013). Another study supported the similar conclusion in Croatian population to develop chronic obstructive pulmonary disease where there was no evidence for the association of A1L2437 (Matokanovic et al., 2012).

In our study, we evaluated the influence of HSPA1B and HSPA1Lgene variants in gene on ECA risk by association analysis in 78 ECA patients and 100 cancerfree control samples from Northeast India. No previous data has been reported on A1B and A1L from this region of India. The $A \rightarrow G$ substitution in A1B1267 is a silent mutation which does not result any variation in the protein (Vargas-Alarcon et al., 2002) but the heterozygous A/G variant can alter the expression of A1B by interfering with the secondary structure and mRNA stability (Wu et al., 2004), thus may affect its antiapoptotic as well as immune modulatory functions, resulting in predisposition and prognosis of different types of cancers. Previously it is a reported marker in different diseases like nasopharyngeal carcinoma, Parkinson's disease, renal diseases (Wu et al., 2004). Whereas $T \rightarrow C$ substitution in A1L2437 results in amino acid substitution of Met $\rightarrow$ Thr at 493 position of amino acid sequence in the protein (Fekete et al., 2006). However, in another study has shown no association in the allelic and genotypic distribution between patients and controls for these two polymorphisms in Chinese population (Liu et al., 2007).

Our data suggests that the homozygous variant $(\mathrm{G} / \mathrm{G})$ genotype of A1B is associated with increased risk of ECA when compared with control samples from Northeast India. Whereas in case of A1L gene the ancestral genotype (T/T) was found more in cases and controls than the homozygous variant $(\mathrm{C} / \mathrm{C})$. Statistically when compared all the genotypes of each gene with control, a significant association was found with $\mathrm{P}<0.05$ to develop ECA in North eastern part of India.

A contradictory conclusion was reported in Costa Rican population where the heterozygous $(\mathrm{A} / \mathrm{G})$ genotype of A1B 1267 was associated with increased risk of gastric 
cancer and duodenal ulcer than the homozygous $(\mathrm{G} / \mathrm{G})$ genotype. Where as in case of A1L2437 homozygous variant genotype $(\mathrm{C} / \mathrm{C})$ were significantly less susceptible to gastric cancer than homozygous wild (T/T) genotype, that is concordance to our study. (Ferrer-Ferrer et al.,2013). The allelic frequency of A1L2437 is not associated to develop the oesophageal carcinoma in our study. Another contradictory result was reported in Hungarian population (Szondy et al., 2012) where G/G genotype of A1B1267 is a negative prognostic factor for survival in SCLC patients. A meta analysis also has recently reported (Kuang et al., 2014) where the heterozygous polymorphism of A1B1267 may contribute to susceptibility of cancer, in a Caucasian population.

Similar findings with our study was reported in Chinese, Han and Tunisian populations where homozygous was associated with an increased risk of developing cancer but not in heterozygous genotype (Mestiri et al., 2001). A significant association of the allele G of A1B gene with spondyloarthropathies in a Mexican population has been reported (Vargas-Alarcon et al., 2002). In our study the and G/G genotype of A1B1267 and T/T genotype of A1L2437 was found significantly associated with the patients of ECA, when compared with control samples from this population. The similar conclusion was reported on hepatocellular carcinoma and chronic hepatitis cases in Indian population, it was observed that the homozygous variant allele was implicated as a possible risk factor. (Medhi et al., 2013).

It can be concluded that the present study provides marked evidence that Polymorphisms of A1B1267 and A1L2437 genes are associated with the development of ECA in a population in Northeastern region of India. The A1L2437 is not associated to develop the disease with respect to the allelic distribution compared with controls. However, one of the limitations of this study is the limited sample size. Larger and well designed studies are warranted to confirm our observations. Particularly the gene-environment interactions and mechanisms of $\mathrm{A} 1 \mathrm{~B}$ and $\mathrm{A} 1 \mathrm{~L}$ in regulating the proliferation of ECA cells are important facets of research. Moreover, data from this study showed betel quid consumption to be a highly significant risk factor, followed by smoking and tobacco chewing. Alcohol consumption alone was found as a non significant risk factor but joint effect with smoking, betel nut and tobacco significantly increases the risk of developing oesophageal carcinoma in North Eastern population of India.

\section{Acknowledgements}

We thank all individuals who volunteered to participate in this study and the members of the Department of Applied Sciences, Gauhati University and Department of Gastroenterology, Gauhati Medical College Hospital, specially the members of Endoscopy OT. The authors acknowledge Indian Council of Medical Research for financial support.

\section{References}

Akhtar S, Sheikh AA, Qureshi HU (2012). Chewing areca nut, betel quid, oral snuff, cigarette smoking and the risk of oesophageal squamous-cell carcinoma in South Asians: a multicentre case-control study. Eur J Cancer, 48, 655-61.

Asea A, Kraeft SK, Kurt-Jones EA, et al (2000). HSP70 stimulates cytokine production through a CD14-dependant pathway, demonstrating its dual role as a chaperone and cytokine. Nat Med, 6, 435-42.

Boiocchi C, Osera C, Monti MC, et al (2014). Are Hsp70 protein expression and genetic polymorphism implicated in multiple sclerosis inflammation? J Neuroimmunol, 268, 84-8.

Chen J, Zhang N, Ling Y, et al (2011). Alcohol consumption as a risk factor for oesophageal adenocarcinoma in North China. Exp Med, 224, 21-7.

Chitra S, Ashok L, Anand L, et al (2004). Risk factors for esophageal cancer in Coimbatore, southern India: a hospitalbased case-control study. Indian J Gastroenterol, 23, 19-21.

Chouchane L, Ahmed SB, Baccouche S, et al (1997). Polymorphism in the tumor necrosis factor-alpha promotor region and in the heat shock protein 70 genes associated with malignant tumors. Cancer, 80, 1489-96.

Daugaard M, Rohde M, Jaattela M (2007). The heat shock protein 70 family: Highly homologous proteins with overlapping and distinct functions. FEBS Lett, 581, 3702-10.

Dar NA, Bhat GA, Shah IA, Iqbal B, et al (2012). Hookah smoking, nass chewing, and oesophageal squamous cell carcinoma in Kashmir, India. Br J Cancer. 107, 1618-23.

Favatier F, Bornman L, Hightower LE, et al (1997). Variation in hsp gene expression and Hsp polymorphism: do they contribute to differential disease susceptibility and stress tolerance? Cell Stress Chaperones, 2, 141-55.

Fekete A, Viklicky O, Hubacek JA, et al (2006). Association between heat shock protein 70 s and toll-like receptor polymorphisms with long-term renal allograft survival. Transpl Int. 19, 190-6.

Ferrer-Ferrer M, Malespin-Bendaña W, Ramirez V, et al (2013). Polymorphisms in genes coding for HSP-70 are associated with gastric cancer and duodenal ulcer in a population at high risk of gastric cancer in Costa Rica. Arch Med Res, 44, 467-74.

Ganesh B, Talole SD, Dikshit R (2009). Tobacco, alcohol and tea drinking as riskfactors for esophageal cancer: A case-control study from Mumbai, India. Cancer Epidemiol, 33, 431-4.

Giri PA, Singh KK, Phalke DB (2014). Study of sociodemographic determinants ofesophageal cancer at a tertiary care teaching hospital of Western Maharashtra,India. South Asian J Cancer, 3, 54-6.

Gopala Krishnappa BR, Vijay CR, Ramesh C, et al (2013). Trends in oesophagus and Stomach cancer incidence in Bangalore, India Gulf J Oncol, 1, 42-50.

Holmes RS, Vaughan TL (2007). Epidemiology and pathogenesis of esophageal cancer. Semin Radiat Oncol, 17, 2-9.

Hanahan D, Weinberg RA (2011). Hallmarks of cancer: the next generation. Cell, 144, 646-74.

Ke L (2002). Mortality and incidence trends from esophagus cancer in selectedgeographic areas of China circa 1970-90. Int J Cancer, 102, 271-4.

Kuang D, Chen W, Song YZ, et al., 2014. Association between the HSPA1B $\pm 1267 \mathrm{~A} / \mathrm{G}$ polymorphism and cancer risk: a meta-analysis of 14 case-control studies. Asian Pac J Cancer Prev, 15, 6855-61.

Kummee P, Tangkijvanich P, Poovorawan Y, et al (2007). Association of HLA-DRB $1 * 13$ and TNF-alpha gene polymorphisms with clearance of chronic hepatitis B infection and risk of hepatocellular carcinoma in Thai population. J Viral Hepat, 14, 841-8.

Layke JC, Lopez PP (2006). Esophageal cancer: a review and 
Polymorphisms in Heat Shock Proteins A1B and AlL (HOM) as Risk Factors for Oesophageal Carcinoma in Northeast India update. Am Fam Physician, 73, 2187-94.

Lee CH, Lee JM, Wu DC, et al (2005). Independent and combined effects of alcohol intake, tobacco smoking and betel quid chewing on the risk of esophageal cancer in Taiwan. Int J Cancer, 113, 475-82.

Liu J, Cheng J, Peng J, et al (2007). Effects of polymorphisms of heatshock protein 70 gene on ischemic stroke, and interaction with smoking in China. Clin Chim Acta, 384, 64-8.

Lovett MC, Coates JR, Shu Y, et al (2014). Quantitative assessment of hsp70, IL-1 $\beta$ and TNF- $\alpha$ in the spinal cord of dogs with E40K SOD1-associated degenerative myelopathy. Vet J, 200, 312-7.

Matokanovic M, Rumora L, Popovic-Grle S, et al., (2012). Association of hsp70-2 (+1267A/G), hsp70-hom (+2437T/C), HMOX-1 (number of GT repeats) and TNF-alpha $(+489 \mathrm{G} / \mathrm{A})$ polymorphisms with COPD in Croatian population. Clin Biochem, 45, 770-4.

Medhi S, Sarma MP, Asim M, et al (2013). Genetic variants of heat shock proteinA1L2437 and A1B1267 as possible risk factors for hepatocellular carcinoma in India. $J$ Viral Hepat, 20, 141-7.

Meimaridou E, Gooljar SB, Chapple JP (2009). From hatching to dispatching: themultiple cellular roles of the Hsp70 molecular chaperone machinery. J Mol Endocrinol, 42, 1-9.

Mestiri S, Bouaouina N, Ahmed SB, Khedhaier, et al (2001). Genetic variation in the tumor necrosis factor-alpha promoter region and in the stress protein hsp70-2: susceptibility and prognostic implications in breast carcinoma. Cancer, 91, 672-8.

Milner RE, Busaan J, Michalak M (1992) Isolation and characterization of different C-terminal fragments of dystrophin expressed in Escherichia coli. Biochem J, 288, 1037-44.

Kurkalang S, Banerjee A, Dkhar H, et al (2015). Precocious anaphase and expression of Securin and p53 genes as candidate biomarkers for the early detection in areca nutinduced carcinogenesis. Mutagenesis, 30, 381-9.

Pandeya N, Williams G, Green AC, et al (2009). Australian Cancer Study. Alcohol consumption and the risks of adenocarcinoma and squamous cell carcinoma of the esophagus. Gastroenterol, 136, 1215-24,

Phukan RK, Ali MS, Chetia CK, et al (2001). Betel nut and tobacco chewing; potential risk factors of cancer of oesophagus in Assam, India. Br J Cancer, 85, 661-7.

Prabhu A, Obi KO, Rubenstein JH (2013). Systematic review with meta-analysis:race-specific effects of alcohol and tobacco on the risk of oesophageal squamous cell carcinoma. Aliment Pharmacol Ther, 38, 1145-55.

Rohde M, Daugaard M, Jensen MH, et al (2005). Members of the heat-shock protein 70 family promote cancer cell growth by distinct mechanisms. Genes Dev, 19, 570-82.

Sambrook J, Fritsch EF, Maniatis T (1990). Molecular cloning: a laboratory manual, $2^{\text {nd }}$ edn. cold spring harbor, NY, USA: Cold Spring Harbor Laboratory Press, 73.

Szondy K, Rusai K, Szabo AJ, et al (2012). Tumor cell expression of heat shock protein (HSP) 72 is influenced by HSP72 [HSPA1B A(1267)G] polymorphism and predicts survival in small Cell lung cancer (SCLC) patients. Cancer Invest, 30, 317-22.

Vabulas RM, Ahmad-Nejad P, Ghose S, et al (2002). HSP70 as endogenous stimulus of the Toll/interleukin-1 receptor signal pathway. J Biol Chem, 277, 15107-12.

Vargas-Alarcon G, Londoño JD, Hernandez-Pacheco G, et al (2002). Heat shock protein 70 gene polymorphisms in Mexican patients with spondyloarthropathies. Ann Rheum Dis, 61, 48-51.

Waters JS, Tait D, Cunningham D, et al (2002). A multicentre 